\title{
The functional complexity of [NiFe] hydrogenases in sulfate reducing bacteria (genus; Desulforvibrio spp)
}

\author{
Saidu Haruna ${ }^{1, ~}$, Hamzat Ibiyeye Tijani ${ }^{2}$, Yusuf Hindatu ${ }^{3}$, Jibrin Ndejiko Mohammed ${ }^{4}$, \\ Bashir Mohammed Abubakar ${ }^{5}$, Mohammed Sulaiman ${ }^{1}$, Abdulrahman Idris ${ }^{6}$ \\ ${ }^{1}$ Department of Biological Sciences, Gombe State University, Gombe, Nigeria \\ ${ }^{2}$ Department of Biochemistry, Bauchi State University Gadau, Bauchi, Nigeria \\ ${ }^{3}$ Faculty of Bioscience \& Medical Engineering, Universiti Teknologi Malaysia, 81310 Skudai, Johor-bahru, Malaysia \\ ${ }^{4}$ Department of Microbiology, Ibrahim Badamasi Babangida University Lapai, Niger, Nigeria \\ ${ }^{5}$ Department of Biological Sciences, Bauchi State University Gadau, Bauchi, Nigeria \\ ${ }^{6}$ Department of Microbiology, Kaduna State University, Kaduna, Nigeria
}

\section{Email address:}

saiduharunn@yahoo.com (S. Haruna),yusufhindat@yahoo.com (Y. Hindatu),janyzrux@gmail.com (H. I. Tijani), ndejiko@gmail.com (J. N. Mohammed), elbash1150@yahoo.com (B. M. Abubakar), sumulsu@yahoo.com (M. Sulaiman), abdurrahman.idris@kasu.edu.ng (A. Idris)

\section{To cite this article:}

Saidu Haruna, Hamzat Ibiyeye Tijani, Yusuf Hindatu, Jibrin Ndejiko Mohammed, Bashir Mohammed Abubakar, Mohammed Sulaiman, Abdulrahman Idris. The Functional Complexity of [NiFe] Hydrogenases in Sulfate Reducing Bacteria (Genus; Desulforvibrio spp). American Journal of Bioscience and Bioengineering. Vol. 2, No. 1, 2014, pp. 1-7. doi: 10.11648/j.bio.20140201.11

\begin{abstract}
Sulfate-reducing bacteria are categories of bacteria and archaea that can obtain energy by oxidizing organic compounds or molecular hydrogen $\left(\mathrm{H}_{2}\right)$ while reducing sulfate $\left(\mathrm{SO}_{4}{ }^{2-}\right)$ to hydrogen sulfide $\left(\mathrm{H}_{2} \mathrm{~S}\right)$. By analysis, these organisms "respire" sulfate rather than oxygen, a form of anaerobic respiration, the oxidation of hydrogen by the primary genus of Sulfate Reducing Bacteria (Desulfovibrio, Desulfovibrio desulfuricans) is catalyzed by enzymes called Hydrogenases. Three basic types of hydrogenases have been widely isolated from the primary genus of sulfate-reducing bacteria Desulfobibrio which differ in their structural subunits, metal compositions, physico-chemical characteristics, amino acid sequences, immunological activities, structural gene configuration and their catalytic properties. Broadly, hydrogenases can be considered as iron containing hydrogenases and nickel-containing hydrogenases. The iron-sulfurcontaining hydrogenase enzyme contains two ferredoxin-type (4Fe-4S) clusters and typical iron-sulfur center believed to be involved in the activation of $\mathrm{H}_{2}$ yet it is the most sensitive domain to $\mathrm{CO}$ and $\mathrm{NO}_{2}^{-}$. eventhough it is not featured in all species of genus Desulfovibrio. The nickel-(iron-sulfur)-containing hydrogenases, [NiFe] hydrogenase posses two 4Fe-4S centers and one 3Fe-xS cluster in addition to nickel and have been found in all species of Desulfovibrio with strong resistance to $\mathrm{CO}$ and $\mathrm{NO}_{2}^{-}$so far investigated. The genes encoding the large and small subunits of a periplasmic and membrane-bound species of the [NiFe] hydrogenase have been cloned in Escherichia coli and sequenced, however the functional complexity of the hydrogenase system remained unexplored as a result of the metabolic diversity in Desulfovibrio spp. The [NiFe] hydrogenase plays an important role in the energy metabolism of Desulfovibrio spp. Thus, the expression of the encoded structural genes would be an excellent marker for the metabolic functionalities under specific inducible environment.
\end{abstract}

Keywords: Hydrogenases, Sulfate-Reducing Bacteria, Iron-Containing Hydrogenases, Genus: Desulfovibrio, Nickel-Iron-Containing-Hydrogenases, Nickel-Iron-Selenium-Containing Hydrogenases

\section{Introduction}

Sulfate-reducing bacteria employs different carbon sources as electron donor and channels the sulphate moiety as the respiratory substrate while other molecules are being reduced [1]. SRB especially the genus Desulforvibrio ultimately require hydrogen for their metabolism [2]. Moreover, such utilization of molecular hydrogen serve as generation intermediate specially for chemiosmotic gradient via organic molecule degradation [3] and lead to production of hydrogen in sulfate-depleted media [4]. Two major models have been described to explain the energy 
transduction mechanism in sulfate-reducing bacteria. The first is the so-called "hydrogen cycling" model, described by Odom and Peck [5], suggests that molecular hydrogen originated from lactate oxidation (an important intermediate metabolite) is produced within the cytoplasm and diffuses across the membrane; then, a periplasmic hydrogenase will oxidizes the diffused hydrogen while the electrons are transferred along the cytoplasmic membrane and used to reduce electron acceptors, such as sulfate, in a vectorial electron transfer process [6]. More recently, [7] proposed a generalized system that describes how does hydrogen help in different environmental condition to improves the growth of SRB species (D. Vulgaris). The first unified model shows that, the process of hydrogen transformation throughout in $D$. vulgaris confers an enormous important the metabolic system of the species. The second model states that the physiological function of hydrogen metabolism is to regulate the redox potential of electron carriers such as ferredoxin and/or cytochromes, in order to control the exchange of proton and vectorial electron sensation to stimulate and produce a membrane bound proton motive force [8]. Thus, the metabolic pathway designated by these two models reveals that $\mathrm{H}_{2}$ shows an important part in the bioenergetics of sulfatereducing bacteria; however, the specialized protein for reverse oxidation of molecular $\mathrm{H}_{2}$ is termed Hydrogenases.

Nickel-Iron hydrogenase enzyme; form a critical type of protein known to oxidize the reversible activation of molecular $\mathrm{H}_{2}$ in both eukaryotes and some prokaryotes. The active site of the enzyme establishes a bases for chemical reaction by which the organism save and utilize energy through redox mechanism (Figure 1). This process is very important especially for deoxygenic bacteria such as sulfate-reducing bacteria of the genus Desulfovibrio.[9-11]. One of the practical applications of this enzyme has proven to be a renewable and more environmentally friendly energy source to such an extent that, scientist can engineer the condition to enable the [NiFe] hydrogenase to induce unilateral hydrogen production. In addition, enzymes which are analogues of $[\mathrm{NiFe}]$ hydrogenase can also generate hydrogen gas.

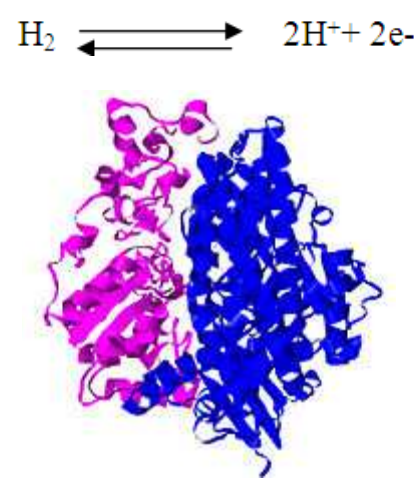

Figure 1. three dimensional structure of [NiFe] hydrogenase in D. Vulgaris.; the small subunit (magenta); the large subunit (blue) both are configured by Jmo l (J-mol)with coordinates from 1H2A.pdb.

\subsection{Structural Classification of Hydrogenase Enzymes}

The enzymes are categorised into two major division based on the metals found in their active sites. The [Fe] containing hydrogenases and the $[\mathrm{NiFe}]$ hydrogenases including the sub-group of the [NiSeFe] hydrogenases (where a cysteinyl ligand of the nickel site is replaced by a seleno-cysteine) [12]. These enzymes have been characterized to differ in terms of their specific activity and bio-directionality [13].

Basically, the Hydrogenase enzyme are further categorised in to one of the following types depending on metal atoms they constitute in their active site. The three types are; $[\mathrm{NiFe}],[\mathrm{FeFe}]$, and $[\mathrm{Fe}]$. Until recently, the iron containing are known to be metal free, Thauer et al., [13] in his experiment described that, metal free enzyme now called Iron containing hydrogenase are previously identified as metal free they are now called Iron containing hydrogenase enzymes [14], this include no iron-sulfur cluster and mononuclear Fe active site in contrast to [FeFe] hydrogenases. [FeFe] and $[\mathrm{NiFe}]$ even though contained different metals in their active site yet share some structural similarities. The similarities are;

$\checkmark \quad$ The entire enzyme possessed active site and a few Fe$\mathrm{S}$ clusters that are found beneath the protein.

$\checkmark \quad$ The active site contained metallocluster with each metal; they are coordinated by cyanide $\left(\mathrm{CN}^{-}\right)$ligands and carbon monoxide (CO). The active site induces catalysis. [15]

The number and cellular localization of hydrogenase varies within different species of Desulfovibrio. For example, $D$. gigas has a single variant of $[\mathrm{NiFe}]$ hydrogenase while $D$. Vulgaris Hildenborough contains three types of hydrogenase, an [NiFe] hydrogenase located in the membrane, an [Fe] hydrogenase in the periplasm and an $[\mathrm{NiFeSe}]$ hydrogenase on the membrane adjacent to the cytoplasm [33]. The difference in their structural configuration is described in figure 2 .

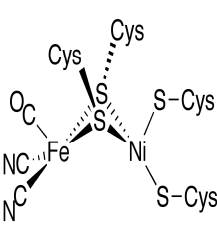

[NiFe] $\mathrm{H}_{2}$ ase

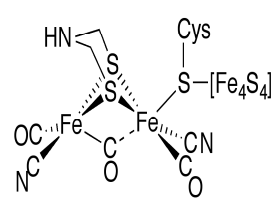

$[\mathrm{FeFe}] \mathrm{H}_{2}$ ase

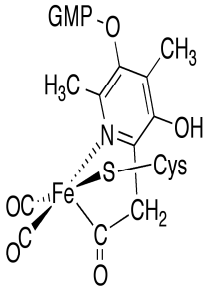

[Fe] $\mathrm{H}_{2}$ ase
Figure 2. Structural configuration of different forms of hydrogenase found in $S R B$

"The sulfate-reducing bacterium Desulfovibrio vulgaris Hildenborough possesses four periplasmic hydrogenases that facilitate the oxidation of molecular hydrogen. These include an [Fe] hydrogenase, an [NiFeSe] hydrogenase, and two [NiFe] hydrogenases encoded by the hyd, hys, hynl, and hyn 2 genes, respectively. These enzymes are present ubiquitously in both Archaea and Bacteria, including many 
SRB. The fully sequenced Desulfovibrio vulgaris Hildenborough has a total of six hydrogenases" [16]. The four enzymes including a soluble [Fe] hydrogenase $(H y d)$ are periplasmic; implies that they presumably involved in hydrogen catalysis [17], two membrane-associated [NiFe] hydrogenase isozymes (Hyn1 and Hyn2) [15], and a membrane-associated $[\mathrm{NiFeSe}]$ hydrogenase $(H y s)$ are all involved in hydrogen oxidation [18].

\subsection{Structure of [NiFe] Hydrogenases}

X-ray crystallography was employed for the study and the structure of [NiFe] hydrogenase enzymes was obtained from the unified results of five different sulfate-reducing bacteria viz; D. Desulfuricans [19] , D. Frutosovorans [2] [20] D. Vulgaris Miyazaki F, [21] D. gigas, , and Desulfomicrobium baculatum. [12]. As described above, the enzyme in D. vulgaris Miyazaki $\mathrm{F}$ shown in Figure 1 consist of larger subunit (blue) with a molecular mass of $62.5 \mathrm{kDa}$, and $\mathrm{Ni}-\mathrm{Fe}$ active site while the smaller subunit is in magenta with a molecular mass of $28.8 \mathrm{kDa}$, and contains the Fe-S clusters at the active site.

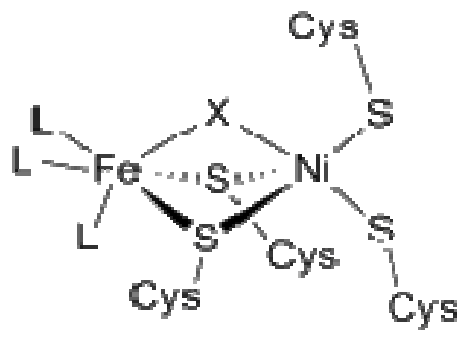

Figure 3. Structural configuration of [NiFe] hydrogenase from D. vulgaris

Based on the X-ray crystallography and infrared spectra, the $[\mathrm{NiFe}]$ enzymes active site were reported to consist of (S-Cys $)_{4} \mathrm{Ni}(\mu-\mathrm{X}) \mathrm{Fe}(\mathrm{CO})(\mathrm{CN})_{2}$; the generic ligand coded $\mathrm{X}$ occur in form of either an sulphur, oxide, hydroperoxide, or a hydroxide in an oxidized state only (Figure 3 ). The nickel atom functions in redox reactions while the iron atom is consistently in a Fe (II) coordination state. [22]. However, they were identified as two carbon monoxide $(\mathrm{C} \equiv \mathrm{O})$ molecules and one cyanide $\left({ }^{-} \mathrm{C} \equiv \mathrm{N}\right)$ molecule. $[23]$

\subsection{Application of [NiFe] Hydrogenases}

The $[\mathrm{NiFe}]$ Hydrogenase enzyme have numerous role to play over a wide range of biotechnology A preliminary characterization of the electron carrier system of newly isolated strain indicates the presence of a membrane bound [NiSeFe] hydrogenase, a periplasmic tetrahemic cytochrome c3, APS reductase and desulforubidin as dissimilatory bisulfite reductase [24]. The enzymes is capable of ensuring both the catalysis and consumption of
$\mathrm{H}_{2}$, usually this is a typical characteristics of hydrogenase family. The most important application of Hydrogenase enzymes are;

$\checkmark \quad$ as anode catalysts in enzyme fuel cells,

$\checkmark \quad$ the harnessing of the $\mathrm{H}_{2}$ oxidation reaction to provide a source of low-potential electrons for use in reduction reactions, and

$\checkmark \quad$ The enzymatic photo-generation of $\mathrm{H}_{2}$

The hydrogenase activity can provide an important resource for the cells, as an "energy valve", when they are forced to grow in a medium, where the electron donor or acceptors are scarce. This may be relevant in environments, where bacteria can use any available metallic structures, driving to bio-corrosion processes [25]26] such as those occurring in ships hulls or heat exchangers.

\subsection{Biological function of [NiFi] Hydrogenases}

Scientific hypothesis suggested that, if earth were to be occupied with hydrogen, hydrogenase enzymes were potentially made to form molecular hydrogen which can be used by other microbes in a given ecosystem as a sources of energy [27]. Such microbial communities are usually bottom dwellers, thriving in a region where sources of light for photosynthesis is very minimal, thus hydrogenase enzyme evolved to generate energy for itself and other systematic biota.

Hydrogenase function to act as a "valve" in anoxic metabolism by regulating the hyper reducing equivalent in photosynthesis microbes [28]. In addition, hydrogenase were found to induces trans-membrane motive force result in to bioremediation of chlorinated compound, recovery of heavy metal contaminant from contaminated site. Examples of the microbes are pathogenic bacteria and parasite function as energy producer and virulence [27].

\section{Mechanism of the [NiFe] Hydrogenase}

There had been a controversy over a precise mechanism behind [NiFe] hydrogenase. The debate started in 2009 where Higuchi and his fellows examined the structure of Desulfovibrio vulgaris Miyazaki base on X-ray crystallography and spectroscopic data [23] they proposed that, during the excited state of catalysis, the metal $(\mathrm{Fe})$ found at the active site of the enzyme remained un-static while the $\mathrm{Ni}$ metal ions involve in the catalysis (redox chemistry). The two redox stage of the enzymes catalysis are;

$\checkmark \quad$ Inactive redox states

$\checkmark \quad$ Active redox states and

$\checkmark \quad$ The CO-inhibited states (Figure 4). 


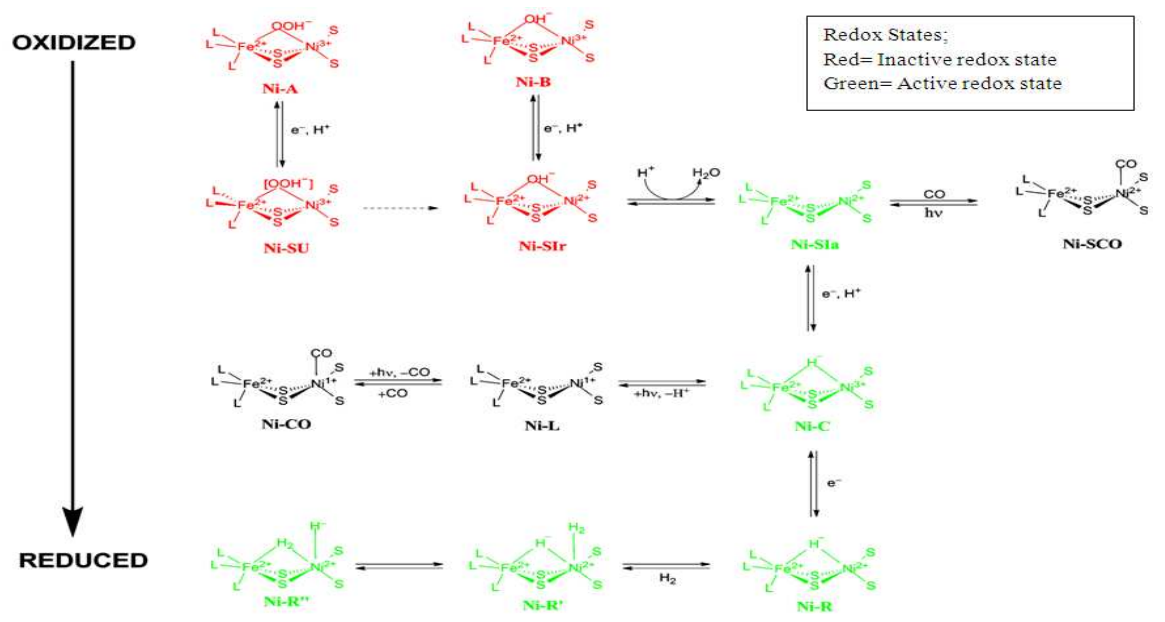

Figure 4. Redox transitions of the metal active site of [NiFe] hydrogenase [22].

(1)Resting redox state (inactive)

[NiFe] oxidizes in two forms; the unsteady state (Ni-A) and steady state $\mathrm{Ni}$ (Ni-B). The two stages are activated through one electron reduction. The rate conversion of $\mathrm{Ni}$ $\mathrm{B}$ to $\mathrm{Ni}$-sr occurs in second while that of $\mathrm{Ni}$-su take place about one hour. The difference in the activation mode of the two stages was as a result of the differences in nature of ligand that bridge the two redox stage. Condensation reaction take place at $\mathrm{Ni}-\mathrm{Slr}$ state which result to the formation of Ni-Sla state by releasing water, Hence the termed condensation reaction [29]

(2)Active Redox state;

Unlike the inactive form of [ $\mathrm{NiFe}]$ hydrogenase enzymes, the active states constitute 3 forms viz; Ni-Sla, Ni-R and $\mathrm{Ni}-\mathrm{C}$. Ni-C is also called the light sensitive state formed through electro-reduction of Ni-Sla. Ni-C is the most sensitive form because it signifies vividly that hydrogen catalysis take place in [NiFe] hydrogenase active site [23].

(3)The CO-inhibitory state

$\mathrm{CO}$, is one of the inhibitory factor that bind directly to the Ni metal ion at the active site of the enzyme changing it configuration or conformation to form Ni-Sco, Because Ni$\mathrm{C}$ is photo sensor when illuminated at $100 \mathrm{k}$, forms the NiCo state in the presence of CO. [22]

\subsection{Factors Affecting the Functionality of NiFe Regulation}

The understanding of the systematic hydrogenation and subsequent utilization in microbes is an ultimate goal for basic and applied research. Hydrogen metabolism is accompanied by the role of a key enzyme termed [NiFe] Hydrogenation.

$$
\mathrm{H}_{2} \longleftrightarrow 2 \mathrm{H}^{+}+2 \mathrm{e}^{-}
$$

The constitution of $\mathrm{Ni}$ and $\mathrm{Fe}$ in the enzyme make it metalloenzyme, like other group of metallo-protein, Hydrogenase enzyme is very sensitive to some factors such as high temperature, oxygen inactivation, $\mathrm{CO}, \mathrm{CN}$ and other environmental factors in order to obtained high functional efficiency of the enzyme . Favourable condition must be provided for smooth biotechnological application.

\subsection{Expression of the [NiFe] Hydrogenase Gene in Hydrogenase in Desulfovibrio spp}

An analytical research was carried out to study the cellular function of $[\mathrm{NiFe}]$ hydrogenase by comparing gene (hyd and hyn 1) and novel artificially constructed mutant gene (hys and hyn-1-hyd) [30]. The two distinct growth rates were compared to the wild type growing in a medium where lactate and hydrogen is used as a source of carbon for desulfurization. The expression of gene was studied using microarray hybridization and real time Polymerase Chain Reaction using mRNA. Such mRNA was extracted from cell reported to grow in three different culture condition viz; $5 \%$ hydrogen as a sources of electron donor, $50 \%$ hydrogen and $\mathrm{mM}$ lactate [31].

The results reveals that; the strain growing in $50 \% \mathrm{H}_{2}$ and lactate as a source of electron donor containing enzymes lacking $\mathrm{Fe}$ at the active site were adversely subjected to rudimentary growth. It was further reported that, the cells that suffered the most are the once growing in small amount of hydrogen as low as $5 \% \mathrm{H}_{2}$, hence lacking [NiFeSe] at the active site. Thus the impairment order for the expression of hyd gene follows; lactate $<50 \%$ hydrogen $<5 \%$ while the expression of hys gene follows the reverse case. It is thus suggested that, there is a strong correlation between the intracellular hydrogen concentration and the growth of strain with lactate and 50\% hydrogen where as grow in low amount of intracellular hydrogen is associated with growth in 50\% hydrogen concentration. This induces low activity and high affinity of hydrogenase enzyme containing [NiFeSe], perhaps, it is clearly understood that the concentration of hydrogenase gene, although the distinct influence is yet to be known.

\subsection{Analysis of Distinct Genes Function}

Caffrey and his co-workers had described certainly the expressivity of multiple gene arising from hydrogen and lactate metabolism [30]. It was pointed out that, majority of the expression stimulation were induced in a cell growing 
in a medium rendered with hydrogen of $50 \%, 5 \%$, vol $/$ vol or lactate as source of electron donor. Up regulation of the expression of hyn gene and down regulation of the of the hyd gene were as a results of changes from lactate to hydrogen. Such comparison had establishes a relationship that the gene of hydrogenase enzymes are regulated by several environmental signals. The effectors include the availability of $\mathrm{Fe}^{2+}[32], \mathrm{Ni}^{2+}[33], \mathrm{Se}^{4+}[18]$, and electron acceptors such as oxygen [31].

The expression of Nickel-Iron hydrogenase gene in Desulfovibrio spp; Hydrogen metabolism is a central bioenergetic pathway in Desulfovibrio spp. that involves hydrogen consumption and production under both sulfatereducing and fermentative conditions. Different classes of hydrogenases, viz., [NiFe], [NiFeSe], and [Fe] hydrogenases, have been identified within the genus [34].

Their genes are not uniformly found among Desulfovibrio strains [35]. Complexity of the hydrogen metabolism and the hydrogenase system in Desulfovibrio spp. makes it difficult for the gene to be expressed. The results of the study finally indicate that the transcription of the $[\mathrm{NiFe}]$ hydrogenase gene is correlated with bacterial growth and therefore with the metabolic activity, i.e., sulfate reduction rate, in various Desulfovibrio spp. Thus, the detection of the [NiFe] hydrogenase mRNA appears to be a suitable tool with which to determine metabolically active sample in environmental population. The [NiFe] hydrogenase plays an a crucial role in energy metabolism of Desulfovibrio spp.[36]. Therefore, its expression should be an excellent marker for the metabolic activity of those bacteria in the environment

\subsection{Expression of the [NiFe] Hydrogenase Gene in Pure Cultures (Bioreactor System)}

According to the experiment of [10], the identification of [NiFe] hydrogenase gene fragments and mRNA in Desulfovibrio spp. were investigated and described below in anaerobic methanogenic bioreactor. In parallel, DNA and RNA were reported to be isolated and used as templates for PCR and RT-PCR, respectively. The PCR products were analyzed by DGGE to visualize the individual members of the Desulfovibrio populations. As previously demonstrated by [37] experiments.

[NiFe] hydrogenase mRNA was detected by RT-PCR in various cell of Desulfovibrio spp growing exponentially in a medium where hydrogen or lactate is used as an electron donor in the presence of sulphate. However, no growth of D. desulfuricans DSM 1926 has been reported with hydrogen as an energy source, as was also demonstrated by Devereux et al. [38]. Thus, mRNA was not analyzed. In addition, D. vulgaris DSM 644, D. desulfuricans DSM 1926, and D. baculatus DSM 2555 were grown in lactatesulfate medium. Growth, sulfide production, and the expression of the $[\mathrm{NiFe}]$ hydrogenase gene were monitored until the cultures reached the stationary phase. They described that $[\mathrm{NiFe}]$ hydrogenase mRNA was detectable in exponentially growing cells at 5 to $30 \mathrm{~h}$ after inoculation, as determined by RT-PCR amplification of a ca. 2440-bp

According to the results of [36], DGGE analysis of amplified $[\mathrm{NiFe}]$ hydrogenase gene fragments allows for the differentiation of the various Desulfovibrio strains due to their different migration behaviour caused by sequence variations within their PCR products. [NiFe] hydrogenase gene fragments were amplified from DNA isolated from a sample taken directly out of the reactor. Positive results were also reported to be found for DNA obtained from subsamples that were incubated with hydrogen to induce gene expression, respectively. The corresponding mRNA was detectable in only the bioreactor subsample which was incubated with hydrogen. Agarose gel electrophoresis of the PCR products revealed that the sizes of all amplified fragments were as expected for the $[\mathrm{NiFe}]$ hydrogenase of Desulfovibrio spp. DGGE analysis of the amplified gene fragments showed several bands with identical electrophoresis patterns. However, their results showed that the $[\mathrm{NiFe}]$ hydrogenase gene is present in all Desulfovibrio strains tested so far in Desulfovibrio spp. Which has a single hydrogenase gene, the $[\mathrm{NiFe}]$ hydrogenase is responsible for all the aspects of hydrogen metabolism [10]

Thus the Members of Desulfovibrio spp. containing different numbers of hydrogenase genes, including the following: D. vulgaris DSM 644, which possesses at least three different hydrogenase genes; $D$. desulfuricans DSM 1926, containing two hydrogenase genes; and D. gigas, which contains only the [NiFe] hydrogenase gene [35] have been analysed and the transcription of the $[\mathrm{NiFe}]$ hydrogenase gene were functionally demonstrated in all strains growing in hydrogen-sulfate and lactate-sulfate media.

\section{Conclusion}

The versatility of metabolism experience by sulfatereducing bacteria of the genus Desulfovibrio has established that Hydrogenases are the key enzymes involved in the hydrogen production/consumption [39]. The three most widely researched species of SRB (genus Desulfovibrio) usually show different behaviour in all traits in terms of hydrogen evolution. Differences in the type, localization, specific activity and number of hydrogenase, is responsible for the metabolic performances of the enzymes towards electron donors and acceptors. In fact $D$. vulgaris Hildenborough shows an enhanced hydrogen yield, which is due to the higher specific activity of the [Fe] hydrogenase as compared with [NiFe] and [NiFeSe] hydrogenases in $D$. gigas and $D$. desulfuricans, respectively [10]. It is clear however that all the reducing power of the metabolic chain is driven for hydrogen production vis -avis indicating the existence of hydrogen cycling in SRB [1]. The ability of Desulfovibrio species to handle hydrogen in a reversible mode shows that these micro-organisms have a high capacity to quickly acclimatize to their system of metabolism despite the variation of environmental changes. Hydrogenase activity 
can provide an important resource for cells when they grow in environments containing scarce electron donors or acceptors. Random and site directed mutagenesis can be done to produce other hydrogenases of high stable function for use in different biotechnological applications. However this SRB require to be treated with biological curiosity as a diversification tool to investigate other factors that could trigger $[\mathrm{NiFe}]$ hydrogenase efficiency in SRB.

\section{References}

[1] Carepo, M., J. Baptista, A. Pamplona, G. Fauque, J. Moura, and M. Reis, Hydrogen metabolism in $<\mathrm{i}>$ Desulfovibrio desulfuricans $</ i>$ strain New Jersey (NCIMB 8313)comparative study with $<\mathrm{i}>\mathrm{D}$. vulgaris $</ \mathrm{i}>$ and $<\mathrm{i}>\mathrm{D}$. gigas $</ i>$ species. Anaerobe, 2002. 8(6): p. 325-332.

[2] Volbeda, A., M.-H. Charon, C. Piras, E.C. Hatchikian, M. Frey, and J.C. Fontecilla-Camps, Crystal structure of the nickel-iron hydrogenase from Desulfovibrio gigas. 1995.

[3] Pereira, I.A.C., Respiratory membrane complexes of Desulfovibrio, in Microbial Sulfur Metabolism. 2008, Springer. p. 24-35.

[4] Traore, A.S., C.E. Hatchikian, J. Le Gall, and J.-P. Belaich, Microcalorimetric studies of the growth of sulfate-reducing bacteria: comparison of the growth parameters of some Desulfovibrio species. Journal of bacteriology, 1982. 149(2): p. 606-611.

[5] Odom, J. and H. Peck, Hydrogen cycling as a general mechanism for energy coupling in the sulfate - reducing bacteria, Desulfovibrio sp. FEMS Microbiology Letters, 1981. 12(1): p. 47-50.

[6] Peck, H.D., J. LeGall, P.A. Lespinat, Y. Berlier, and G. Fauque, A direct demonstration of hydrogen cycling by $<\mathrm{i}>$ Desulfovibrio vulgaris $</ \mathrm{i}>$ employing membrane-inlet mass spectrometry. FEMS microbiology letters, 1987. 40(2): p. 295-299.

[7] Noguera, D.R., G.A. Brusseau, B.E. Rittmann, and D.A. Stahl, A unified model describing the role of hydrogen in the growth of Desulfovibrio vulgaris under different environmental conditions. Biotechnology and bioengineering, 1998. 59(6): p. 732-746.

[8] LeGall, J. and G. Fauque, Dissimilatory reduction of sulfur compounds. Biology of anaerobic microorganisms, 1988: p. 587-639.

[9] Volbeda, A., E. Garcin, C. Piras, A.L. de Lacey, V.M. Fernandez, E.C. Hatchikian, M. Frey, and J.C. FontecillaCamps, Structure of the [NiFe] Hydrogenase Active Site: Evidence for Biologically Uncommon $\mathrm{Fe}$ Ligands $\perp$. Journal of the American Chemical Society, 1996. 118(51): p. 12989-12996.

[10] Wawer, C., M. Jetten, and G. Muyzer, Genetic diversity and expression of the [NiFe] hydrogenase large-subunit gene of Desulfovibrio spp. in environmental samples. Applied and environmental microbiology, 1997. 63(11): p. 4360-4369.

[11] Eidsness, M.K., R.A. Scott, B.C. Prickril, D.V. DerVartanian, J. Legall, I. Moura, J. Moura, and H.D. Peck, Evidence for selenocysteine coordination to the active site nickel in the
[NiFeSe] hydrogenases from Desulfovibrio baculatus. Proceedings of the National Academy of Sciences, 1989. 86(1): p. 147-151.

[12] Garcin, E., X. Vernede, E. Hatchikian, A. Volbeda, M. Frey, and J. Fontecilla-Camps, The crystal structure of a reduced [NiFeSe] hydrogenase provides an image of the activated catalytic center. Structure, 1999. 7(5): p. 557-566.

[13] Przybyla, A.E., J. Robbins, N. Menon, and H.D. Peck Jr, Structure-function relationships among the nickelcontaining hydrogenases. FEMS Microbiology Letters, 1992. 88(2): p. 109-135.

[14] Thauer, R.K., Biochemistry of methanogenesis: a tribute to Marjory Stephenson: 1998 Marjory Stephenson Prize Lecture. Microbiology, 1998. 144(9): p. 2377-2406.

[15] Fontecilla-Camps, J.C., A. Volbeda, C. Cavazza, and Y. Nicolet, Structure/function relationships of [NiFe]-and [FeFe]-hydrogenases. Chemical reviews, 2007. 107(10): p. 4273-4303.

[16] Heidelberg, J.F., R. Seshadri, S.A. Haveman, C.L. Hemme, I.T. Paulsen, J.F. Kolonay, J.A. Eisen, N. Ward, B. Methe, and L.M. Brinkac, The genome sequence of the anaerobic, sulfate-reducing bacterium Desulfovibrio vulgaris Hildenborough. Nature biotechnology, 2004. 22(5): p. 554559.

[17] Huynh, B.H., M.H. Czechowski, H.-J. Krüger, D.V. DerVartanian, H.D. Peck, and J. LeGall, Desulfovibrio vulgaris hydrogenase: a nonheme iron enzyme lacking nickel that exhibits anomalous EPR and Mössbauer spectra. Proceedings of the National Academy of Sciences, 1984. 81(12): p. 3728-3732.

[18] Valente, F.M., C.C. Almeida, I. Pacheco, J. Carita, L.M. Saraiva, and I.A. Pereira, Selenium is involved in regulation of periplasmic hydrogenase gene expression in Desulfovibrio vulgaris Hildenborough. Journal of bacteriology, 2006. 188(9): p. 3228-3235.

[19] Matias, P.M., C.M. Soares, L.M. Saraiva, R. Coelho, J. Morais, J. Le Gall, and M.A. Carrondo, [NiFe] hydrogenase from Desulfovibrio desulfuricans ATCC 27774: gene sequencing, three-dimensional structure determination and refinement at $1.8 \AA$ and modelling studies of its interaction with the tetrahaem cytochrome c 3. JBIC Journal of Biological Inorganic Chemistry, 2001. 6(1): p. 63-81.

[20] Volbeda, A., L. Martin, C. Cavazza, M. Matho, B.W. Faber, W. Roseboom, S.P. Albracht, E. Garcin, M. Rousset, and J.C. Fontecilla-Camps, Structural differences between the ready and unready oxidized states of [NiFe] hydrogenases. JBIC Journal of Biological Inorganic Chemistry, 2005. 10(3): p. 239-249.

[21] Higuchi, Y., T. Yagi, and N. Yasuoka, Unusual ligand structure in $\mathrm{Ni}-\mathrm{Fe}$ active center and an additional $\mathrm{Mg}$ site in hydrogenase revealed by high resolution X-ray structure analysis. Structure, 1997. 5(12): p. 1671-1680.

[22] Chiou, T.-W. and W.-F. Liaw, Nickel-thiolate and ironthiolate cyanocarbonyl complexes: Modeling the nickel and iron sites of $[\mathrm{NiFe}]$ hydrogenase. Comptes Rendus Chimie, 2008. 11(8): p. 818-833.

[23] Ogata, H., W. Lubitz, and Y. Higuchi, [NiFe] hydrogenases: structural and spectroscopic studies of the reaction mechanism. Dalton Transactions, 2009(37): p. 7577-7587. 
[24] Pereira, A., R. Franco, M. Feio, C. Pinto, J. Lampreia, M. Reis, J. Calvete, I. Moura, I. Beech, and A. Lino, Characterization of representative enzymes from a sulfate reducing bacterium implicated in the corrosion of steel. Biochemical and biophysical research communications, 1996. 221(2): p. 414-421.

[25] Chatelus, C., P. Carrier, P. Saignes, M. Libert, Y. Berlier, P. Lespinat, G. Fauque, and J. Legall, Hydrogenase activity in aged, nonviable Desulfovibrio vulgaris cultures and its significance in anaerobic biocorrosion. Applied and environmental microbiology, 1987. 53(7): p. 1708-1710.

[26] Bryant, R.D. and E.J. Laishley, The role of hydrogenase in anaerobic biocorrosion. Canadian Journal of Microbiology, 1990. 36(4): p. 259-264.

[27] Vignais, P.M. and B. Billoud, Occurrence, classification, and biological function of hydrogenases: an overview. Chemical Reviews, 2007. 107(10): p. 4206-4272.

[28] Adams, M.W. and E.I. Stiefel, Biological hydrogen production: not so elementary. Science, 1998. 282(5395): $\mathrm{p}$. $1842-1843$

[29] Lamle, S.E., S.P. Albracht, and F.A. Armstrong, Electrochemical Potential-Step Investigations of the Aerobic Interconversions of [NiFe]-Hydrogenase from Allochromatium $\mathrm{v}$ inosum: Insights into the Puzzling Difference between Unready and Ready Oxidized Inactive States. Journal of the American Chemical Society, 2004. 126(45): p. 14899-14909.

[30] Caffrey, S.M., H.-S. Park, J.K. Voordouw, Z. He, J. Zhou, and G. Voordouw, Function of periplasmic hydrogenases in the sulfate-reducing bacterium Desulfovibrio vulgaris Hildenborough. Journal of bacteriology, 2007. 189(17): p. 6159-6167.

[31] Chhabra, S., Q. He, K. Huang, S. Gaucher, E. Alm, Z. He,
M. Hadi, T. Hazen, J. Wall, and J. Zhou, Global analysis of heat shock response in Desulfovibrio vulgaris Hildenborough. Journal of bacteriology, 2006. 188(5): p. 1817-1828.

[32] Hantke, K., Iron and metal regulation in bacteria. Current opinion in microbiology, 2001. 4(2): p. 172-177.

[33] Vignais, P.M., B. Billoud, and J. Meyer, Classification and phylogeny of hydrogenases1. FEMS microbiology reviews, 2001. 25(4): p. 455-501.

[34] Fauque, G., H. Peck Jr, J. Moura, B. Huynh, Y. Berlier, D. DerVartanian, M. Teixeira, A. Przybyla, P. Lespinat, and I. Moura, The three classes of hydrogenases from sulfatereducing bacteria of the genus $<\mathrm{i}>$ Desulfovibrio $</ \mathrm{i}>$. FEMS microbiology letters, 1988. 54(4): p. 299-344.

[35] Voordouw, G., V. Niviere, F.G. Ferris, P.M. Fedorak, and D.W. Westlake, Distribution of hydrogenase genes in Desulfovibrio spp. and their use in identification of species from the oil field environment. Applied and environmental microbiology, 1990. 56(12): p. 3748-3754.

[36] Rabus, R., T.A. Hansen, and F. Widdel, Dissimilatory sulfate-and sulfur-reducing prokaryotes, in The prokaryotes. 2006, Springer. p. 659-768.

[37] Muyzer, G. and N.B. Ramsing, Molecular methods to study the organization of microbial communities. Water Science and Technology, 1995. 32(8): p. 1-9.

[38] Devereux, R., S. He, C.e.a. Doyle, S. Orkland, D. Stahl, J. LeGall, and W. Whitman, Diversity and origin of Desulfovibrio species: phylogenetic definition of a family. Journal of Bacteriology, 1990. 172(7): p. 3609-3619.

[39] Hansen, T.A., Metabolism of sulfate-reducing prokaryotes. Antonie van Leeuwenhoek, 1994. 66(1-3): p. 165-185. 